\title{
A Simple Expected Volatility (SEV) Index: Application to SET50 Index Options*
}

\author{
Chatayan Wiphatthanananthakul \\ Faculty of Economics, \\ Chiang Mai University \\ and \\ Chulachomklao Royal Military Academy \\ Thailand \\ Michael McAleer \\ Department of Quantitative Economics \\ Complutense University of Madrid
}

March 2009

* This paper was written while the first author was visiting the Econometric Institute, Erasmus School of Economics, Erasmus University Rotterdam, in autumn 2008. The first author wishes to acknowledge the financial support of the Stock Exchange of Thailand, while the second author wishes to thank the Australian Research Council for financial support, and the Erasmus School of Economics for their gracious hospitality and excellent working environment.

* Corresponding Author.

E-mail: chatayan.w@gmail.com and michael.mcaleer@gmail.com

Faculty of Economics, Chiang Mai University, 239 Huay Kaew Road, Suthep District, Chiang Mai, Thailand 50202, Tel. (66) 53942208 


\begin{abstract}
In 2003, the Chicago Board Options Exchange (CBOE) made two key enhancements to the volatility index (VIX) methodology based on S\&P options. The new VIX methodology seems to be based on a complicated formula to calculate expected volatility. In this paper, with the use of Thailand's SET50 Index Options data, we modify the apparently complicated VIX formula to a simple relationship, which has a higher negative correlation between the VIX for Thailand (TVIX) and SET50 Index Options. We show that TVIX provides more accurate forecasts of option prices than the simple expected volatility (SEV) index, but the SEV index outperforms TVIX in forecasting expected volatility. Therefore, the SEV index would seem to be a superior tool as a hedging diversification tool because of the high negative correlation with the volatility index.
\end{abstract}

Keywords: Financial markets, model selection, new products, price forecasting, time series, volatility forecasting. 


\section{Introduction}

In the late 1960s, trading options may not have been widely understood on Wall Street, but options are now much more widely understood in world financial markets, especially in developed countries. This might be attributed to the way in which investors have learned about stock options during the internet boom or the hamburger crisis, or the role that derivatives and options play in modern financial markets.

In 1993, the Chicago Board Options Exchange (CBOE) introduced the CBOE Volatility Index, VIX, which quickly became the benchmark for stock market volatility. As volatility often signifies financial turmoil, the index is often referred to as the "investor fear gauge". The index is based on real-time option prices, and reflects investors' consensus view of future expected stock market volatility.

In September 2008, options trading become an even more important profit tool than a risk diversification tool from investors. The U.S. SEC, U.K. FSA., and Australia stepped into stop short-selling for financial companies in order to stabilize those companies. Recently options have become a significant diversification tool for investors to hedge their portfolios in both expected uptrend and (especially) downturn markets.

The trading volume in SPX options set a new record as 2,182,562 contracts were traded on 6 October 2008, with an average volume of 670,629 contracts per day. On 18 September, the total options volume exceeded 30 million contracts for the first time in history, from the previous day's record of 26 million contracts. Moreover, in the hamburger crisis, the Thailand SET50 options volume increased by $33.5 \%$ and $33 \%$ in September and October, respectively, as compared with August 2008.

One of the keys to options trading is leveraging, whereby leverage allows traders to make a significant amount of money from a relatively small change in price. The trader enjoys the ability of less money at a low investment for bigger bets to hedge a portfolio. In addition, the options trader can minimize exposure to risk from stock investment as a hedge of an under-priced asset relative to its fair value. 
In 29 October 2007, the Stock Exchange of Thailand (SET), with the sub-company Thailand Futures Exchange (TFEX), launched the European-style options written on TFEX with ticker S50myycall/put strike price. For example, S50H09C600 denotes SET50 contract month of March in the year 2009 call option at the strike of 600 . The contract multipliers of the options contracts are 200 Baht per index point

In a competitive market, Singapore and Thailand are planning to integrate the Asian stock market to be more competitive to the world. TFEX should introduce innovative new products to attract foreign investors to invest and hedge their portfolios in Thailand.

The primary purpose of this paper is to simplify the apparently complicated expected volatility formula into a simpler relationship, with the use of SET50 index data becoming a simple expected volatility (SEV) index, and to adapt the new VIX calculation from CBOE to derive an implied volatility index (TVIX) for Thailand SET50 index options. Then we substitute the expected volatilities into the BlackScholes model to predict call and put option prices.

The remainder of the paper is as follows. The volatility index is discussed in Section 2, a brief overview of the volatility index (VIX) from CBOE is given in Section 3, the new VIX formula is presented in Section 4, followed by a simple expected volatility index (SEV) in Section 5, the SET50 index options data for empirical analysis are discussed in Section 6, the Black-Scholes model for substituting the expected volatility to predict call and put option prices is discussed in Section 7, estimation is given in Section 8, and some concluding remarks are presented in Section 9.

\section{Volatility Index}

The idea of estimating implied volatility from options is relatively simple. There is no straightforward method to extract the information. With the large number of option pricing models, many researchers have applied various methods of estimating implied volatilities from option pricing models, especially the Black-Scholes model (see Black and Scholes (1973)). The model was originally developed to estimate implied 
volatility at each exercise price, as in Melino and Turnbull (1990), Nandi (1996), and Bakshi, Cao and Chen (1997).

Option prices calculate implied volatility that represents a market-based estimate of future price volatility, so that implied volatility is regarded as a fear gauge (Whaley (2000)). Implied volatilities are reported by investors, financial news services and other finance professionals. The information content and forecast quality of implied volatility is an important topic in financial markets research.

Latane and Rendleman (1976), Chiras and Manaster (1978), Beckers (1981) and Jorion (1995) provided early assessments of the forecast quality of implied volatility. They concluded that implied volatilities outperform historical standard deviations, although perhaps biased, as a good predictor of future volatility. Christensen and Prabhala (1998) found that implied volatility forecasts are biased, but dominate historical volatility in terms of ex ante forecasting power. Fleming (1998) used a similar volatility measure to show that implied volatilities outperform historical information.

Fleming et al. (1995) showed that implied volatilities from S\&P100 index options yield efficient forecasts of one-month ahead S\&P100 index return volatility, and can also eliminate mis-specification problems. Blair et al. (2001) concluded that the VIX index provides the most accurate forecasts for low- or high-frequency observations, and are also unbiased.

Dennis et al. (2006) found that daily innovations in VIX contain very reliable incremental information about the future volatility of the S\&P100 index. Other studies that attempt to forecast implied volatility or use the information contained in implied volatility to trade in option markets include Harvey and Whaley (1992), Noh et al. (1994), and Poon and Pope (2000).

\section{VIX from CBOE}

VIX measures market expectation of near term volatility conveyed by stock index option prices. The original VIX was constructed using the implied volatilities of eight 
different S\&P100 (OEX) option series so that, at any given time, it represented the implied volatility of an hypothetical at-the-money OEX option with exactly 30 days to expiration from an option-pricing model.

In 2003, the CBOE made two key enhancements to the VIX methodology. The new VIX is based on an up-to-the-minute market estimation of expected volatility that is calculated by using real-time S\&P500 Index (SPX) option bid/ask quotes, and incorporates information from the volatility "skew" by using a wider range of strike prices rather than just at-the-money series with the market's expectation of 30-day volatility, and using nearby and second nearby options.

Until 2006, VIX was trading on the CBOE. The VIX options contract is the first product on market volatility to be listed on an SEC-regulated securities exchange. This new product can be traded from an options-approved securities account. Many investors consider the VIX Index to be the world's premier barometer of investor sentiment and market volatility, and VIX options are a very powerful risk management tool. VIX is quoted in percentage points, just like the standard deviation of a rate of return.

\section{New VIX Procedure}

The New VIX is more robust because it pools the information from option prices over the whole volatility skew, and not just from at-the-money options. The formula used in the new VIX calculation is given by the CBOE as follows:

$$
\sigma^{2}=\frac{2}{T} \sum_{t} \frac{\Delta K_{i}}{K_{i}^{2}} e^{R T} Q\left(K_{i}\right)-\frac{1}{T}\left[\frac{F}{K_{0}}-1\right]^{2},
$$

where

$\sigma \quad=\quad \mathrm{VIX} / 100$ (so that VIX $=\sigma \times 100)$,

$\mathrm{T}=\quad$ Time to expiration (in minutes), 
$\mathrm{F}=$ Forward index level, derived from index option prices (based on at-the-money option prices, the difference between call and put prices is smallest).

The formula used to calculate the forward index level is:

$\mathrm{F}=\quad$ Strike price (at-the-money) $+\mathrm{e}^{\mathrm{RT}} \mathrm{x}($ Call price - Put price),

where

$\mathrm{R}=$ risk-free interest rate is assumed to be $3.01 \%$ (for simplicity, the government T-bills 3 month contract interest rate is used, as the Thailand options contract is a 3 months contract);

$\mathrm{T}=\left\{\mathrm{M}_{\text {current day }}+\mathrm{M}_{\text {settlement day }}+\mathrm{M}_{\text {other days }}\right\} /$ minutes in a year,

where

$\mathrm{M}_{\text {current day }} \quad=\quad$ \# of minutes remaining until midnight of the current day,

$\mathrm{M}_{\text {settlement day }}=$ \# of minutes from midnight until 9:45 am on the TFEX settlement day,

$\mathrm{M}_{\text {other days }}=$ Total \# of minutes in the days between the current day and the settlement day;

$\mathrm{K}_{i}=\quad$ Strike price of $i^{\text {th }}$ out-of-the-money option; a call if $\mathrm{K}_{i}>\mathrm{F}$ and a put if $\mathrm{K}_{i}<\mathrm{F}$;

$\Delta \mathrm{K}_{i} \quad=\quad$ Interval between strike prices - half the distance between the strike on either side of $\mathrm{K}_{i}: \Delta K_{i}=\frac{K_{i+1}-K_{i-1}}{2}$.

$\mathrm{K}_{0}=$ First strike below the forward index level, F;

$\mathrm{Q}\left(\mathrm{K}_{i}\right)=\quad$ The midpoint of the bid-ask spread for each option with strike $\mathrm{K}_{i}$.

(Note: $\Delta \mathrm{K}_{i}$ for the lowest strike is simply the difference between the lowest strike and the next higher strike. Likewise, $\Delta \mathrm{K}$ for the highest strike is the difference between the highest strike and the next lower strike.) 
With the adaptation of the VIX calculation to Thailand SET 50 index options, the Thailand expected volatility (TVIX) can be estimated.

\section{A Simple Expected Volatility Index (SEV Index)}

From the apparently complicated expected volatility formula, this paper tries to simplify the VIX formula into an SEV Index to obtain new results about the information content in option prices. The simplified formulae for the expected volatility index are as follows:

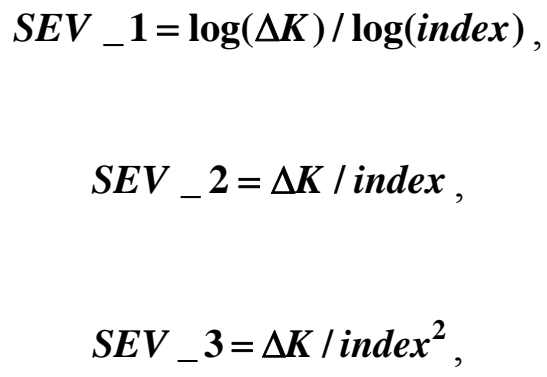

where

$\Delta \boldsymbol{K}=$ the difference between the strike prices.

From Figure 1 in the Appendix, we present graphs of the index, where the data start from 27 January 2008 through to 31 October 2008. Figure 2 illustrates each volatility index time series calculated from the above TVIX and SEV formulae. The summary statistics of the series are given in Table 1, as follows:

- The mean of the SEV_1 index is higher than those of SEV_3 and SEV_2, respectively, but lower than TVIX.

- From Figure 3 in the Appendix, all the indexes are positively skewed. The null hypothesis for the skewness coefficient that conforms to a normal distribution is zero, and this is rejected at the $5 \%$ significance level, with skewness coefficient greater than zero.

- All the indexes display kurtosis, or fat tails.

[Insert Table 1 around here] 
[Insert Figure 2 around here]

\section{Data}

As TFEX index options are European-style, the basic Black-Scholes option pricing model is used, but it causes bias in the calculated implied volatility. Fleming et al. (1995) and Hull and White (1987) have found that the calculation of implied volatilities can eliminate the mis-measurement and bias problem from the near-themoney and close-to-expiry options. Therefore, a total of eight near-the-money closeto-expiry SET50 call and put options prices (four call options and four put options) are used to calculate expected volatility accurately.

Thus, VIX calculation represents the volatility of an hypothetical option that is at-themoney with a constraint 22 trading days (30-day calendar period) to expiration. However, TVIX calculation represents the volatility that is at-the-money with constraint 66 trading days (90-day calendar period) to expiration. For the SEV index, the trading days are used.

Both data series are obtained from Bloomberg (account at the Faculty of Economics, Chiang Mai University and Research Institute, Stock Exchange of Thailand). We obtain high-frequency intraday data, which are data at one-minute intervals between 09.45-12.30 and 14.30-16.55; for a total of 5 hours and 10 minutes each day. The sample period is from 27 January 2008 until 31 October 2008. The contract months are March, June, September, and December 2008. For contract month December 2008, the data are downloaded until 31 October 2008.

In order to estimate TVIX and SEV index and predict for call and put option price, we use the SAS 9.1 software package for the estimation and forecasting of time series data, as it offers a number of features that are not available in traditional econometric software.

As the SAS 9.1 software is used, the trading days for each month are counted through the actual trading days at the SET for SEV index since there is trading. 


\section{The Black-Scholes Model}

The original Black and Scholes (1973) option-pricing model was developed to value options primarily on equities. The modified Black-Scholes European model that is used at the Thailand Futures Exchange (TFEX) has a number of restrictive assumptions, as follows:

1. The options pay no dividends during the option's life $(\mathrm{q}=0)$;

2. European exercise terms dictate that the option can only be exercised on the expiration date;

3. Returns on the underlying asset are lognormally distributed;

4. No commissions are charged.

From the model given below, SET50 index call and put option prices are used to calculate implied volatility.

The TFEX Black-Scholes options pricing model is as follows:

Call option pricing formula:

$$
C=S e^{-q t / 365} \cdot N(d 1)-X e^{-r t / 365} \cdot N(d 2) .
$$

A call option affords the buyer the right to purchase an underlying asset for a fixed price in the future.

Put options pricing formula:

$$
P=X e^{-r t / 365} \cdot(1-N(d 2))-S e^{-q t / 365} \cdot(1-N(d 1)) .
$$

A put option affords the buyer the right to sell the underlying asset for a fixed price in the future: 


$$
\begin{gathered}
d 1=\frac{\ln (S / X)+\left(r-q+\left(V^{2} / 2\right) \cdot(t / 365)\right.}{V \cdot \sqrt{t / 365}} \\
d 2=d 1-V \cdot \sqrt{t / 365}
\end{gathered}
$$

where

$$
\begin{aligned}
& \mathrm{S}=\text { price of underlying asset, } \\
& \mathrm{X}=\text { strike price at maturity date, } \\
& \mathrm{r}=\text { risk-free rate (apply zero-coupon bond at } 3 \text { month maturity to } \\
& \text { calculate options with } 3 \text { months maturity), } \\
& \mathrm{q}=\quad \text { dividend yield of underlying asset }(\mathrm{q}=0) \text {, } \\
& \mathrm{t}=\text { time to maturity (days), } \\
& \mathrm{N}=\text { the cumulative normal distribution function, } \\
& \mathrm{V}=\text { standard deviation of the rate of return during the life of the } \\
& \text { option (the expected volatility or TVIX). }
\end{aligned}
$$

With the Black-Scholes option pricing model, the expected volatilities are substituted to predict call and put option prices at each strike price and expiration.

\section{Estimation}

In order to assess the performance of the TVIX and SEV index, the model fit can be evaluated by measuring the descriptive statistics for the volatility index, as follows: 
Measures of Statistic Fit

\section{Equations}

Mean Square Error

$M S E=\frac{S S E}{n}$

Root Mean Square Error

$R M S E=\sqrt{M S E}$

Mean Absolute Percent Error

$M A P E=\frac{100}{n} \sum_{t=1}^{n}\left|\left(y_{t}-\hat{y}_{t}\right) / y_{t}\right|$

Mean Absolute Error

$M A E=\frac{1}{n} \sum_{t=1}^{n}\left|\hat{y}_{t}-y_{t}\right|$

Adjusted $\mathbf{R}^{2}$

$A D J R^{2}=1-\frac{(n-i)\left(1-R^{2}\right)}{n-p}$

where

$n=$ the number of observations

$p=$ the number of parameters including the intercept

$i=1$ if there is an intercept, 0 otherwise

AIC

$n \ln (M S E)+2 k$

SBIC

$n \ln (M S E)+k \ln (n)$

where $k$ is the number of estimated parameters 
The mean square error (MSE) uses the one-step-ahead forecasts. Root mean square error (RMSE) is useful for determining how accurately the model might predict future observations. Adjusted R-squared $\left(\operatorname{Adj} \mathrm{R}^{2}\right.$ ) is used as a standard model selection criterion. The Akaike information criterion (AIC) (Akaike (1973)) and Schwarz Bayesian Information criterion (SBIC) (Schwarz (1978)) are useful to determine which of several competing nested or non-nested models may fit the data the best. The model with the lowest values of AIC and SBIC is selected as fitting the sample data better.

[Insert Table 2 around here]

The value of adjusted R-squared closest to 1.00 indicates a good fit. The adjusted Rsquared for $\mathrm{SEV}_{-} 1$ is the highest, so $\mathrm{SEV}_{-} 1$ is taken to be the best fitting model.

From Table 2, the AIC values of SEV_2, SEV_1 and TVIX exceed that of SEV_3, with 155,$668 ; 183,217$; and 433,372 ; respectively, so that the best fitting model is SEV_3, with the SEV_2 and SEV_1 models also providing better fits than the TVIX model.

Therefore, from the perspective of adjusted R-squared, AIC and SBIC, the SEV model provides a better fit to the data than does the TVIX model.

[Insert Table 3 around here]

From Table 3, we compare each model across each quarter of the year as the quarterly contract month. In March and June 2008, the adjusted R-squared values of TVIX model are the closest to 1.00, but in September and December, the adjusted R-squared value of SEV_1 model is closest to 1.00 .

Once again, the AIC and SBIC values of the SEV models are smaller than that of the TVIX model, so that the SEV models provide a better fit to the data. 
The overall conclusion to be drawn is that, in terms of goodness of fit measures, our SEV index outperforms the formula used to calculate TVIX. For example, the RMSE of TVIX is larger than that of the SEV index.

[Insert Table 4 around here]

[Refer to Figure 4 around here]

From Table 4 and Figure 4 in the Appendix, we compare actual prices with the predicted prices from each model. In this case, selection of the best fitting model is not so clear, so we calculate the error between the actual and predicted prices.

[Insert Table 5 around here]

[Refer to Figure 5 around here]

Table 5 reports, and Figure 5 in the Appendix illustrates, the statistics relating to the errors. It can be seen that the mean of the error of the SEV_1 index is the lowest, and SEV_2 and SEV_3 have a lower range of errors compared with SEV_1 and TVIX. The errors of SEV_2 and SEV_3 are greater than the errors from SEV_1 and TVIX.

[Insert Table 6 around here]

From Table 6, the percentage error of TVIX is the least, followed by SEV_1, SEV_2 and SEV_3. Additionally, there is a high negative correlation between the SEV_1 index and the index over the year.

[Insert Table 7 around here]

[Insert Table 8 around here] 


\section{Conclusion}

In this paper, we proposed a new and simplified volatility index, VIX, for expected volatility and pricing options from the seemingly complicated expected volatility formula established by the Chicago Board Options Exchange (CBOE). An extensive empirical analysis based on SET50 index options showed that the volatility index for Thailand, TVIX, provided more accurate predictions of option prices than the SEV index as the percent error is less. However, our simple expected volatility (SEV) index model outperformed TVIX in calculating and predicting expected volatility.

Our empirical results suggested that VIX is more accurate in formulating predictions. However, we also showed that the SEV index is more reliable than TVIX from the viewpoint of higher adjusted R-squared values, AIC and SBIC. Therefore, the SEV index would seem to be a superior tool as a hedging diversification tool, especially the SEV_1 index, because of the high negative correlation with the volatility index. 


\section{References:}

Akaike, H. (1974). A new look at the statistical model identification. IEEE Transaction on Automatic Control, AC-19, 716-723.

Bakshi, G., C. Cao and Z. Chen (1997). Empirical performance of the alternative pricing models. Journal of Finance, 52(5), 2003-2049.

Beckers, S. (1981). Standard deviations implied in option prices as predictors of future stock price variability. Journal of Banking and Finance, 5, 363-381.

Black, F. and M. Scholes (1973). The pricing of options and corporate liabilities. Journal Political Economy, 81, 637-654.

Blair, B.J., S.H. Poon and S.J. Taylor (2001). Forecasting S\&P 100 volatility: the incremental information content of implied volatilities and high frequency index returns. Journal of Econometrics, 105, 5-26.

Chiras, D.P. and S. Manaster (1978). The information content of implied volatility. Review of Financial Studies, 6, 659-681.

Christensen, B.J. and N.R. Prabhala (1998). The relation content of option prices and a test of market efficiency. Journal of Financial Economics, 6, 213-234.

Dennis, P., S. Mayhew and C. Stiver (2006). Stock returns, implied volatility innovations, and the asymmetric volatility phenomenon. Journal of Financial and Quantitative Analysis, 41, 381-406.

Fleming, J. (1998). The quality of market volatility forecasts implied by S\&P100 index option prices. Journal of Empirical Finance, 5, 317-345.

Fleming, J., and R.E. Whaley (1995). Predicting stock market volatility: a new measure. Journal of Futures Markets, 15, 295-302.

Harvey, C.R. and R.E. Whaley (1992). Market volatility prediction and the efficiency of the S\&P 100 index option market. Journal of Financial Economics, 31, 4373.

Hull, J. and A. White (1987). The pricing of options on assets with stochastic volatilities. Journal of Finance, 52, 885-899.

Jorion, P. (1995). Predicting volatility in the foreign exchange market. Journal of Finance, 50, 507-528.

Latane, H.A. and R.J. Rendleman (1976). Standard deviations of stock return variance: towards an understanding of stochastic implied volatilities. Review of Financial Studies, 6, 293-326.

Melino, A. and S. Turnbull (1990). The pricing of foreign currency options with stochastic volatility. Journal of Econometrics, 45, 139-265. 
Nandi, S. (1996). Pricing and hedging index options under stochastic volatility: an empirical examination (Undated). Federal Reserve Bank of Atlanta Working Paper, 96-9. Available at SSRN: http://ssrn.com/abstract=4244

Noh, J., R.F. Engle and A. Kane (1994). Forecasting volatility and option prices of the S\&P 500 index. Journal of Derivatives, 2, 17-30.

Poon, S.H. and P.F. Pop (2000). Trading volatility spreads: a test of index option market efficiency. European Financial Management, 6, 235-260.

Schwarz, G. (1978). Estimating the dimension of a model. Annals of Statistics, 6, 461464.

Whaley, R.E. (2000). The investor fear gauge. Journal of Portfolio Management, 26, $12-26$. 
Figure 1: Index time series

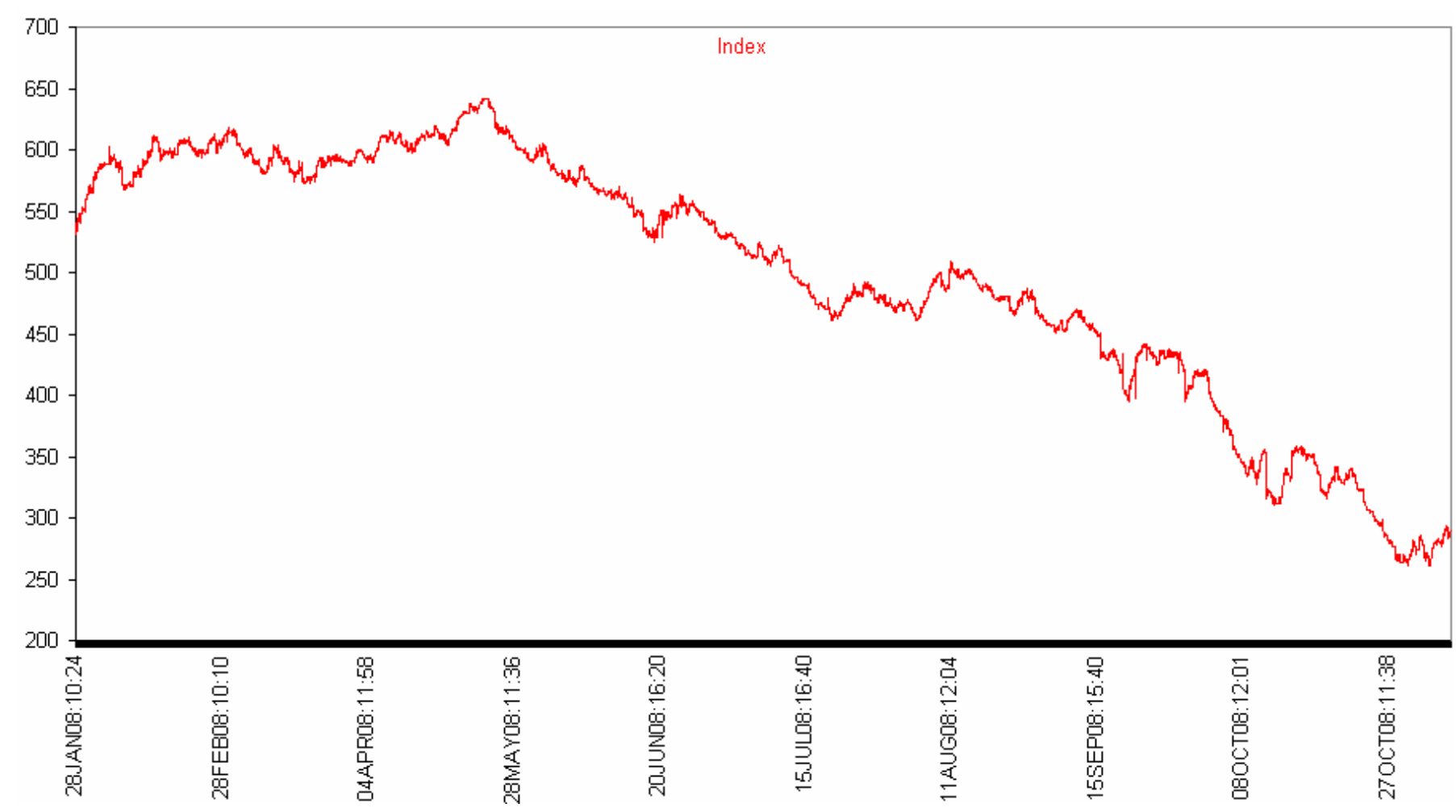


Figure 2.1: SEV_1 index time series 27 January 2008 to 31 October 2008

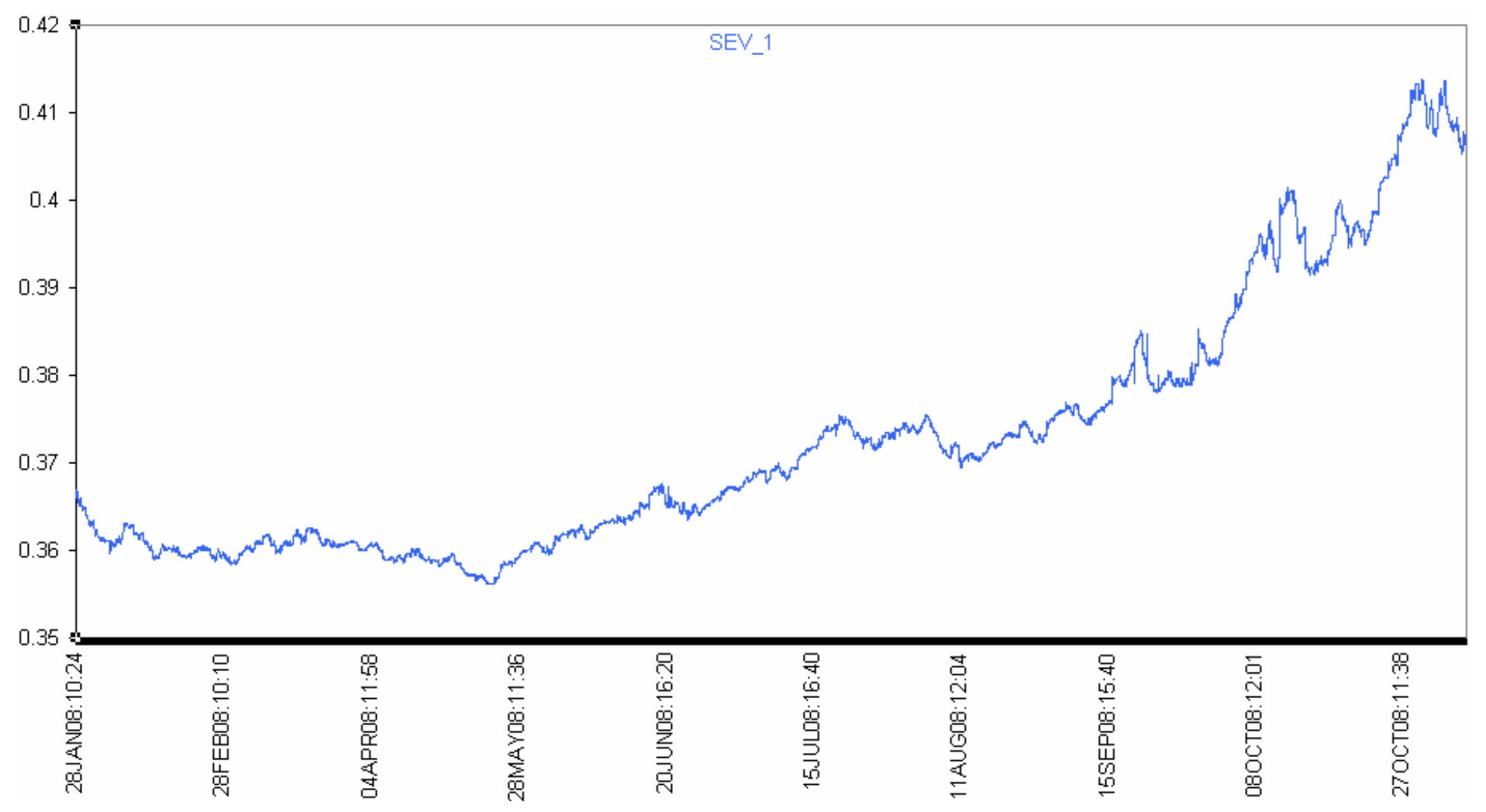


Figure 2.2: SEV_2 index time series 27 January 2008 to 31 October 2008

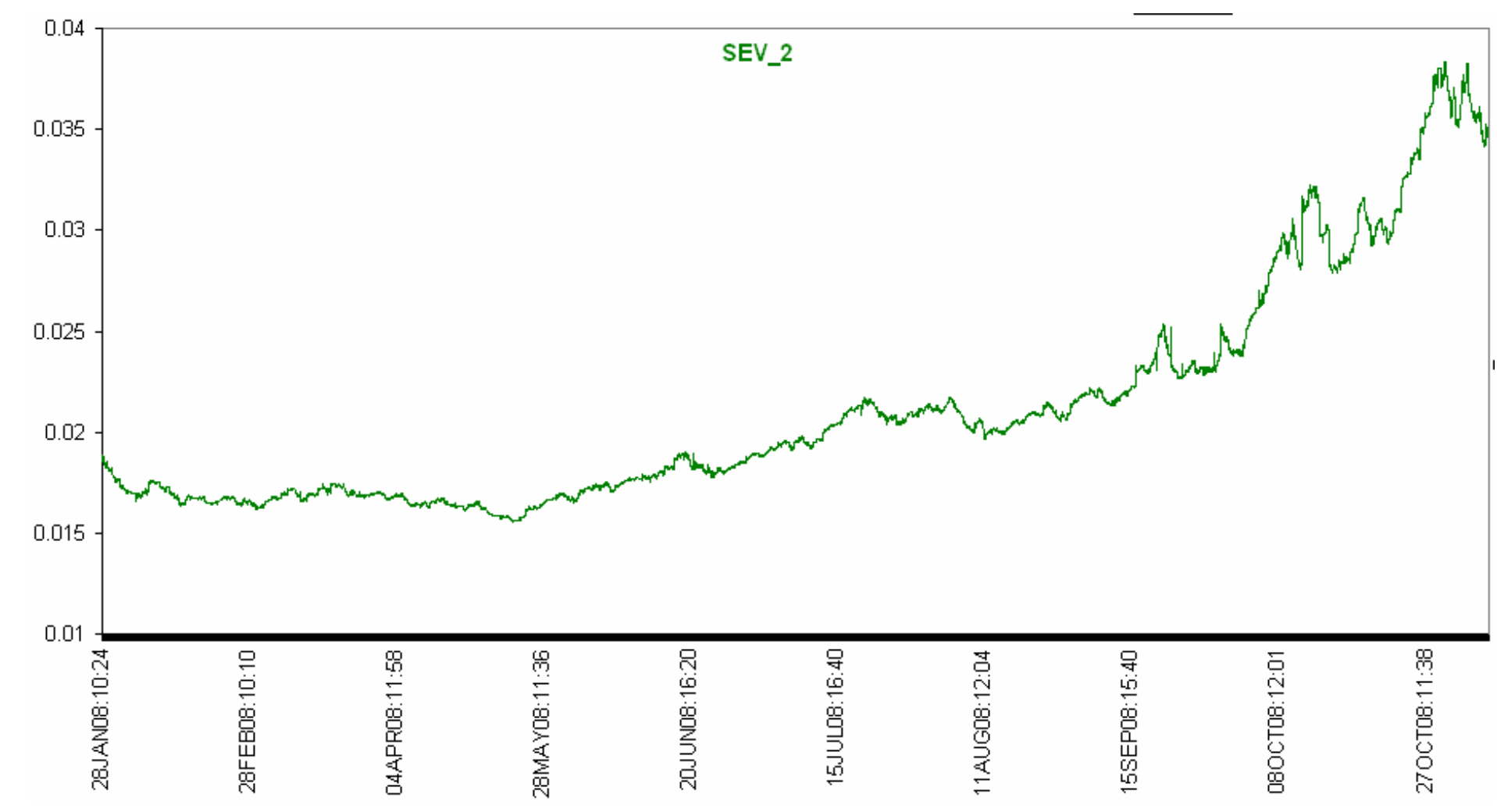


Figure 2.3: SEV_3 index time series 27 January 2008 to 31 October 2008

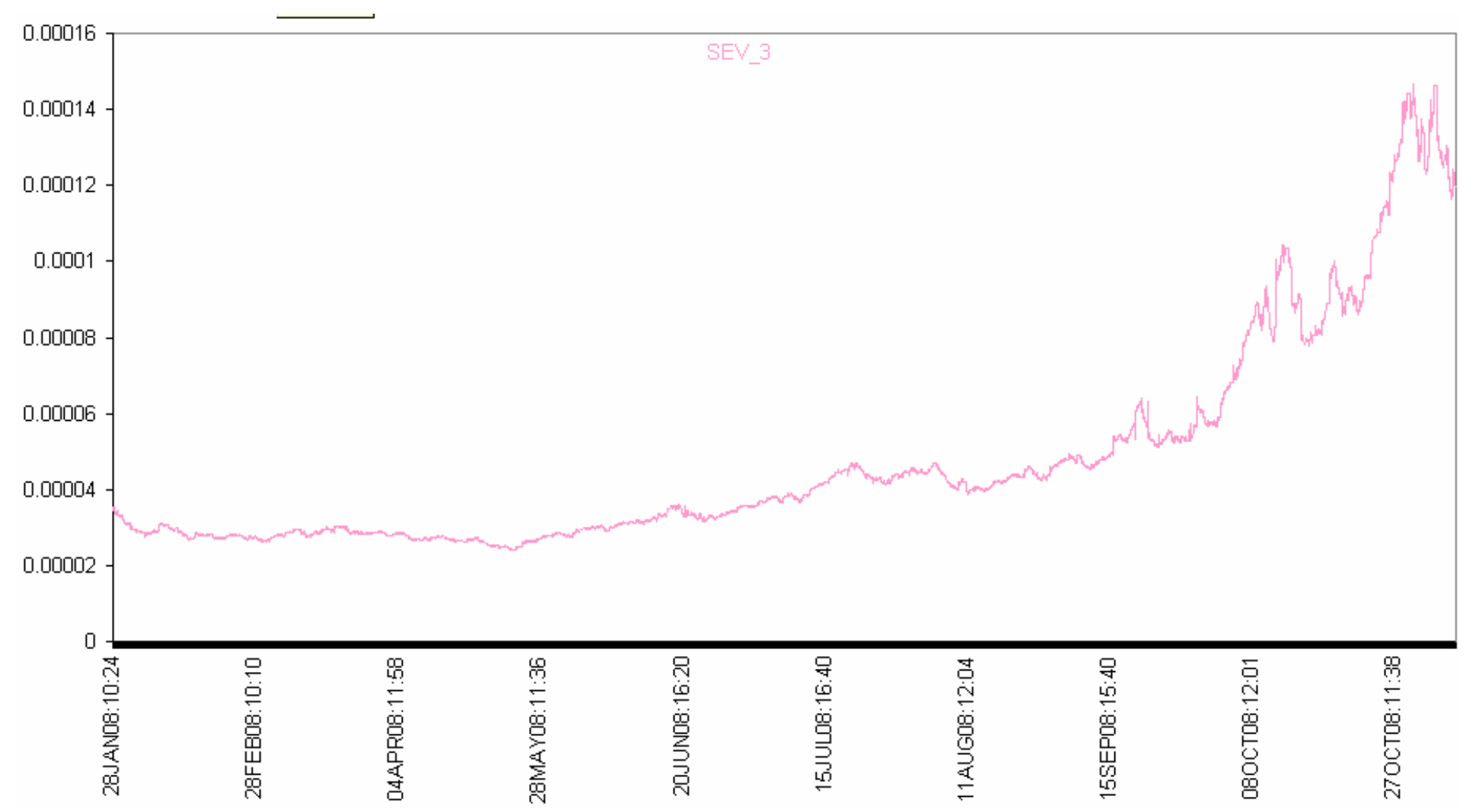


Figure 2.4: TVIX index time series 27 January 2008 to 31 October 2008

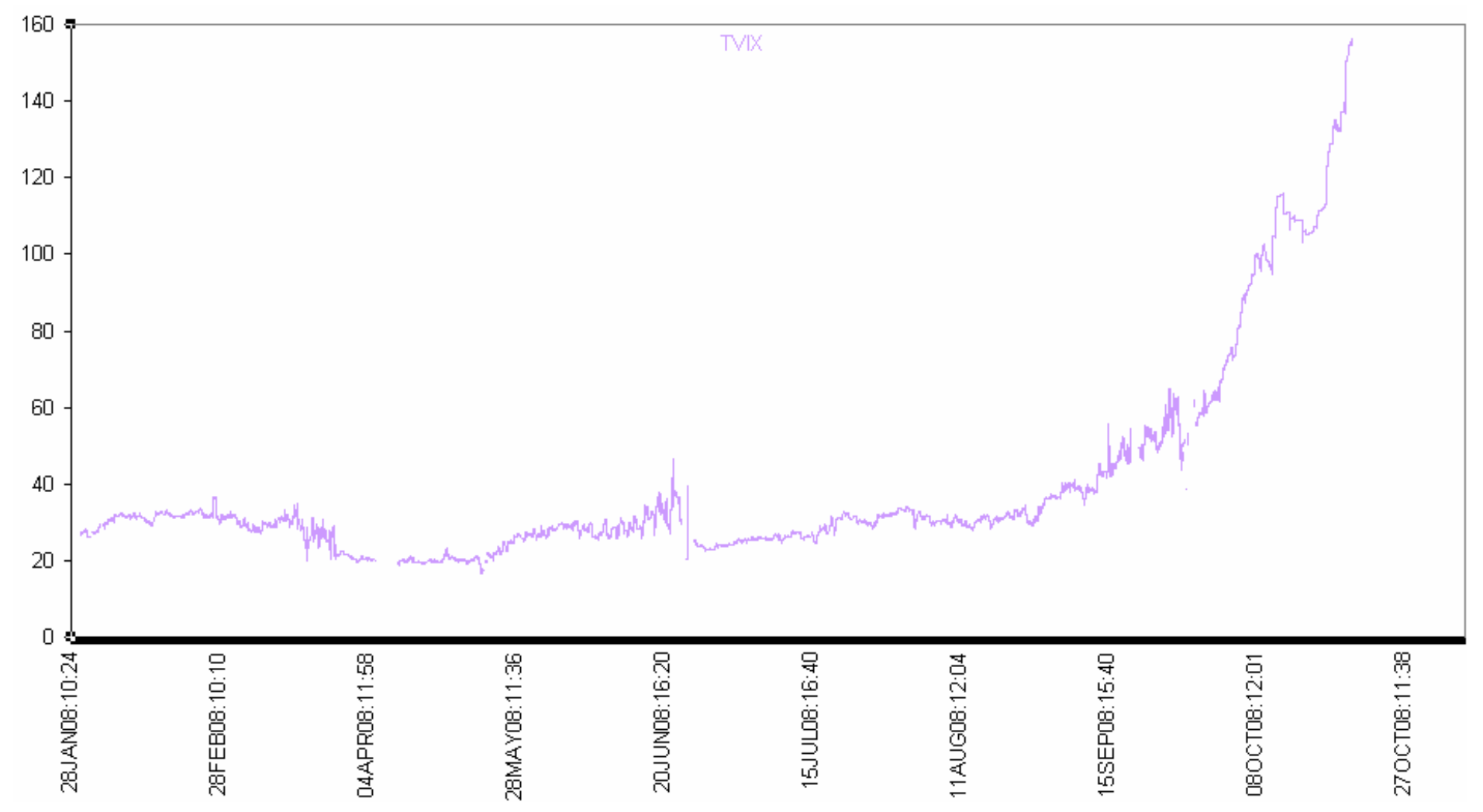


Figure 3.1: SEV_1 index histogram

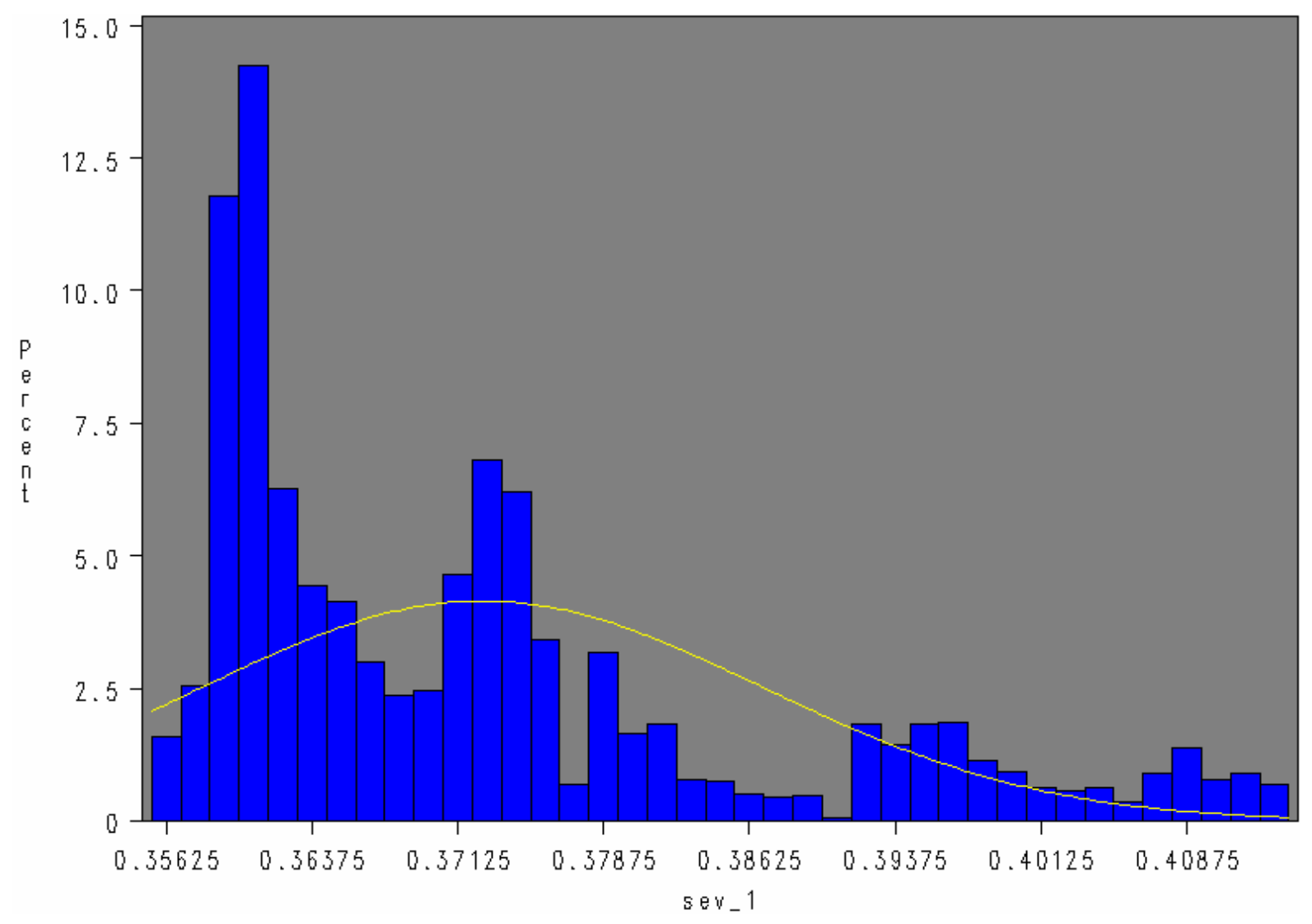


Figure 3.2: SEV_2 index histogram

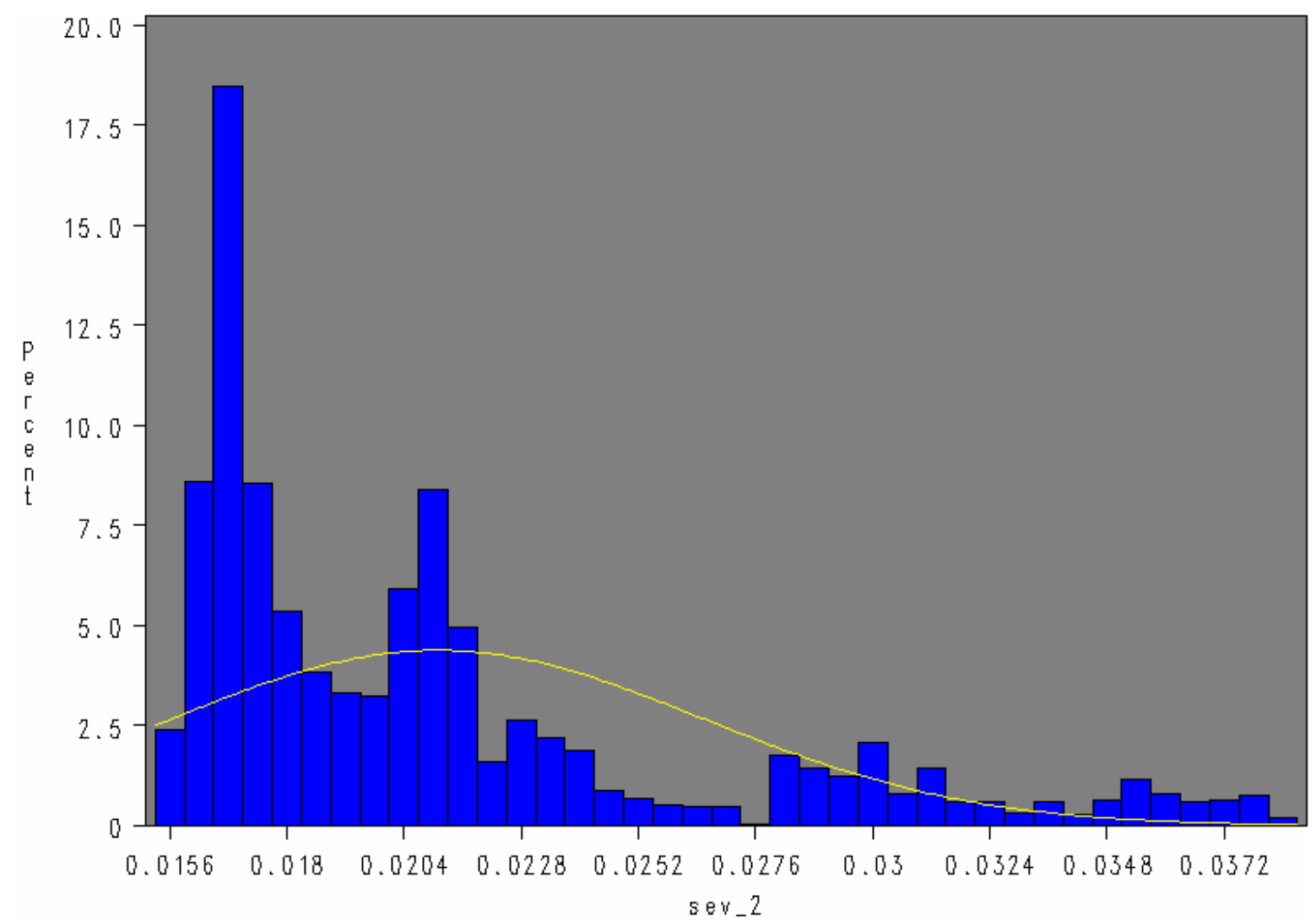


Figure 3.3: SEV_3 index histogram

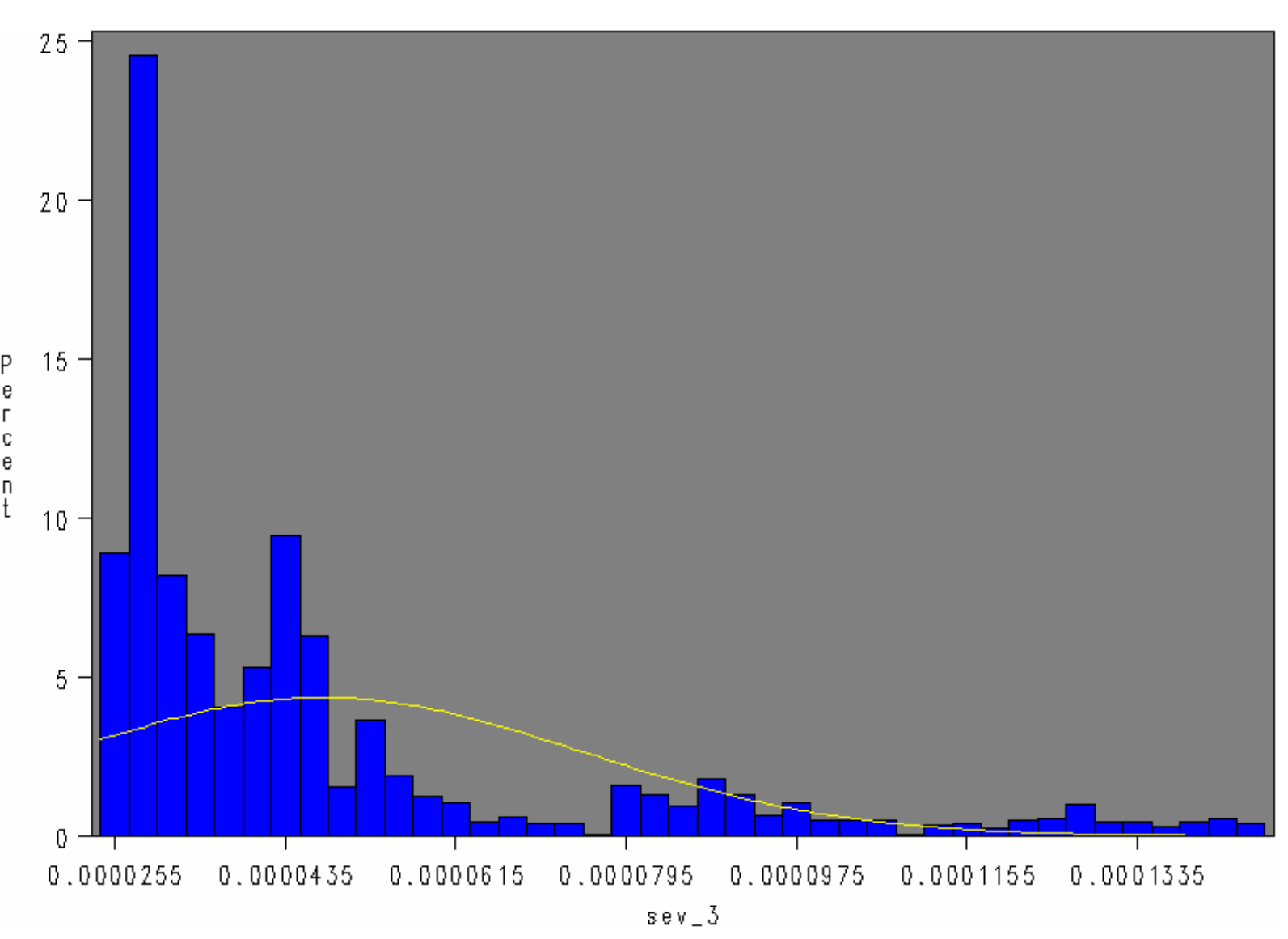

25 
Figure 3.4: TVIX histogram

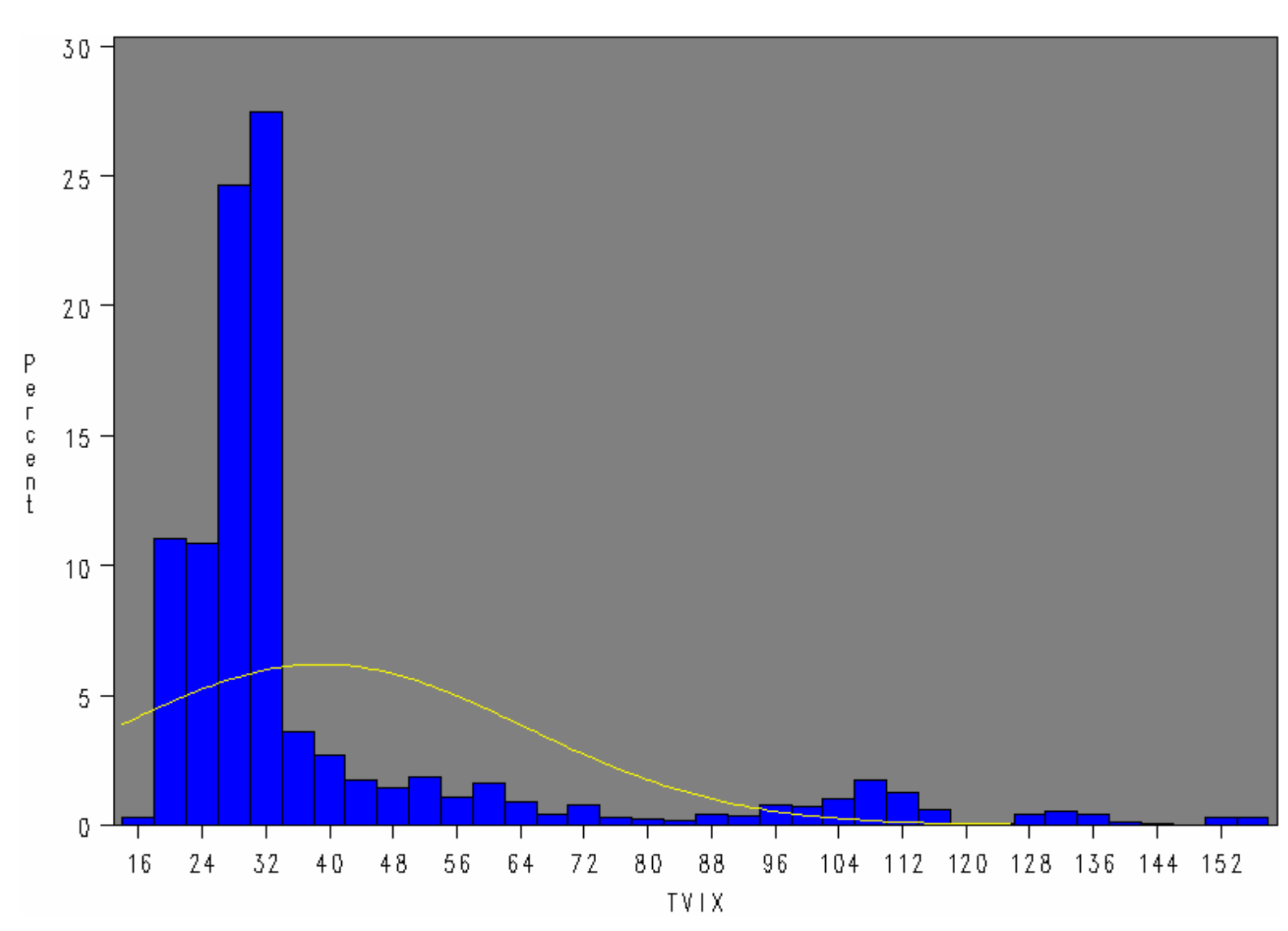

26 
Figure 4.1: Actual price vs. predicted price by SEV_1 index

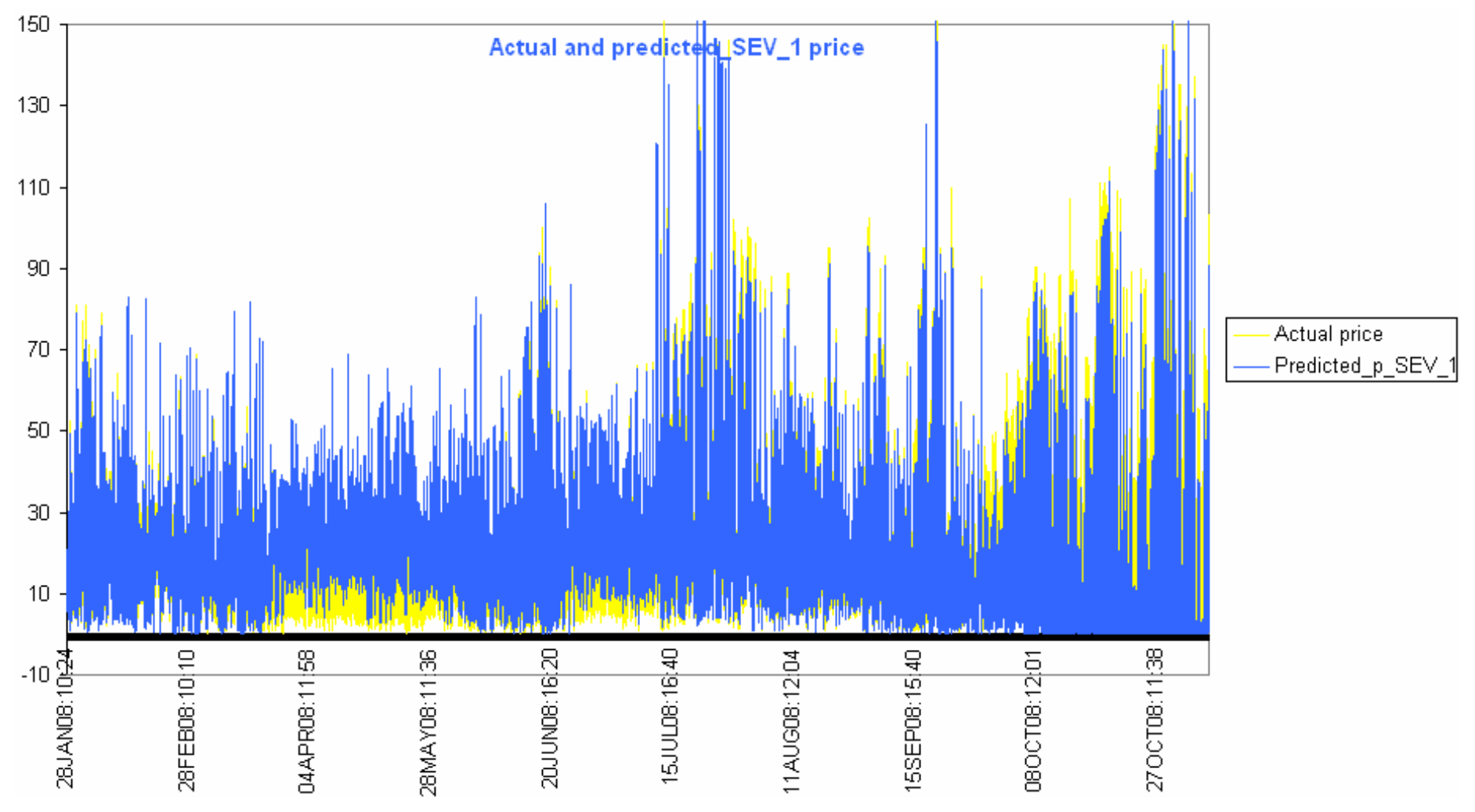


Figure 4.2: Actual price vs. predicted price by SEV_2 index

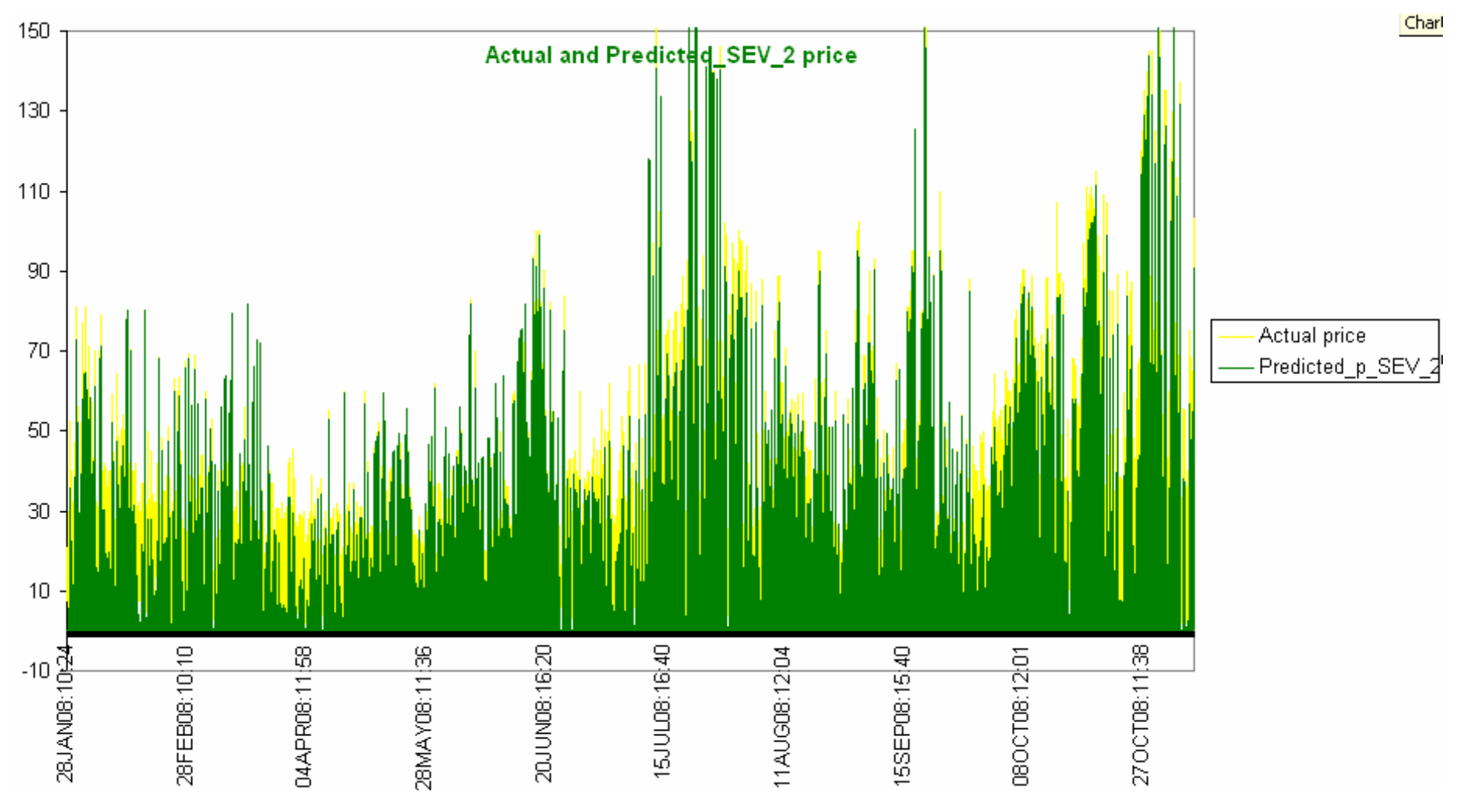


Figure 4.3: Actual price vs. predicted price by SEV_3 index

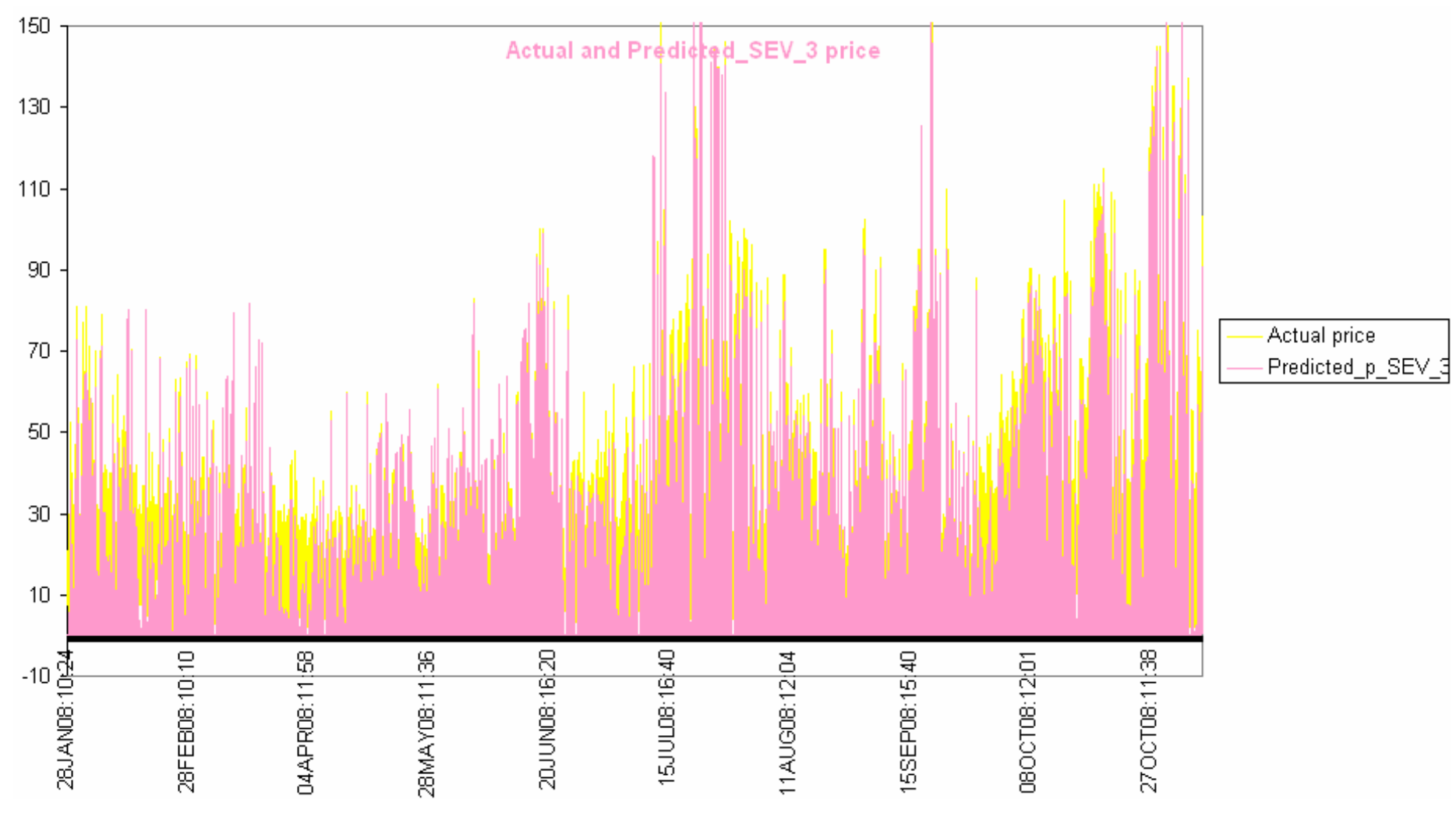


Figure 4.4: Actual price vs. predicted price by TVIX index

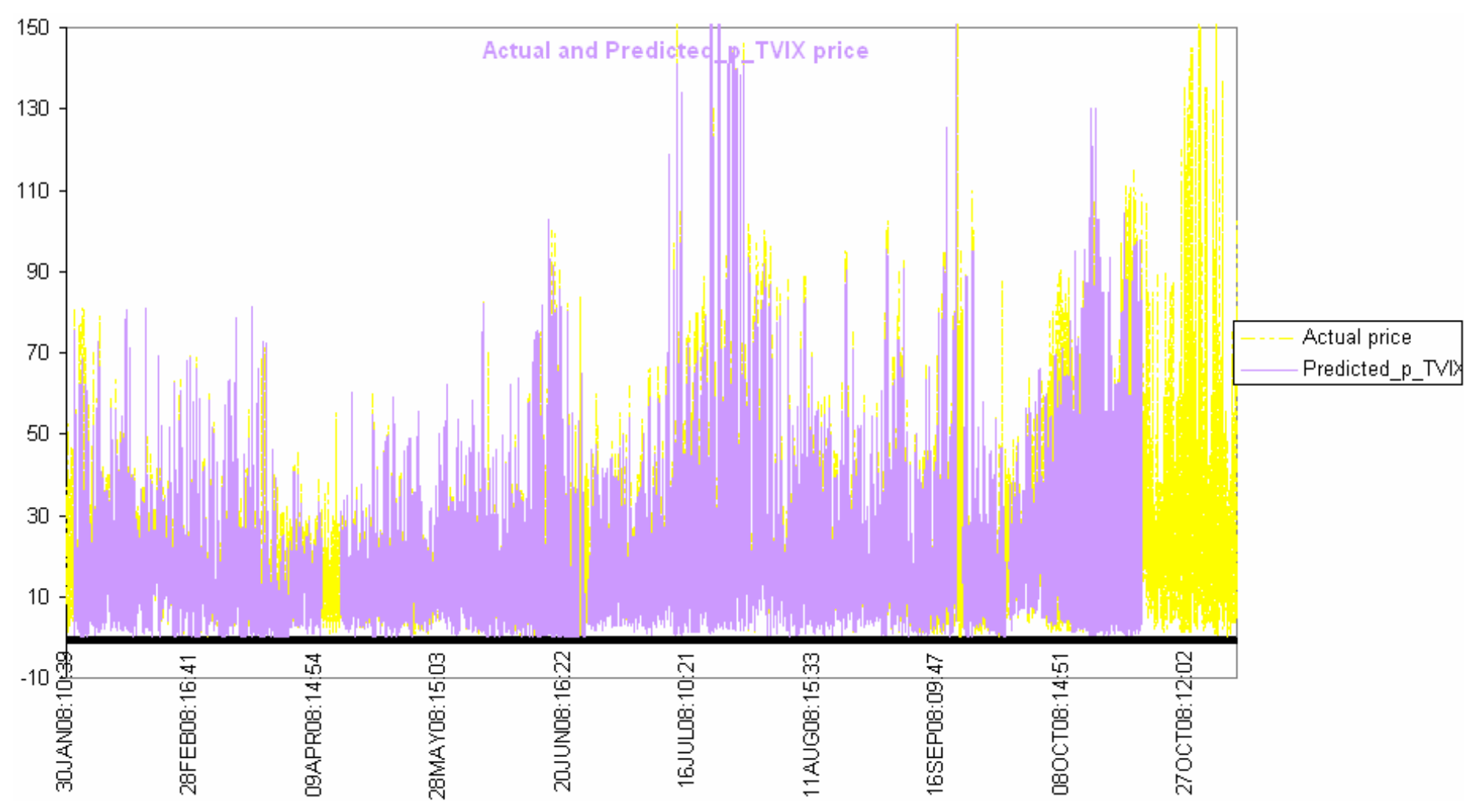


Figure 5.1: Error of SEV 1 index

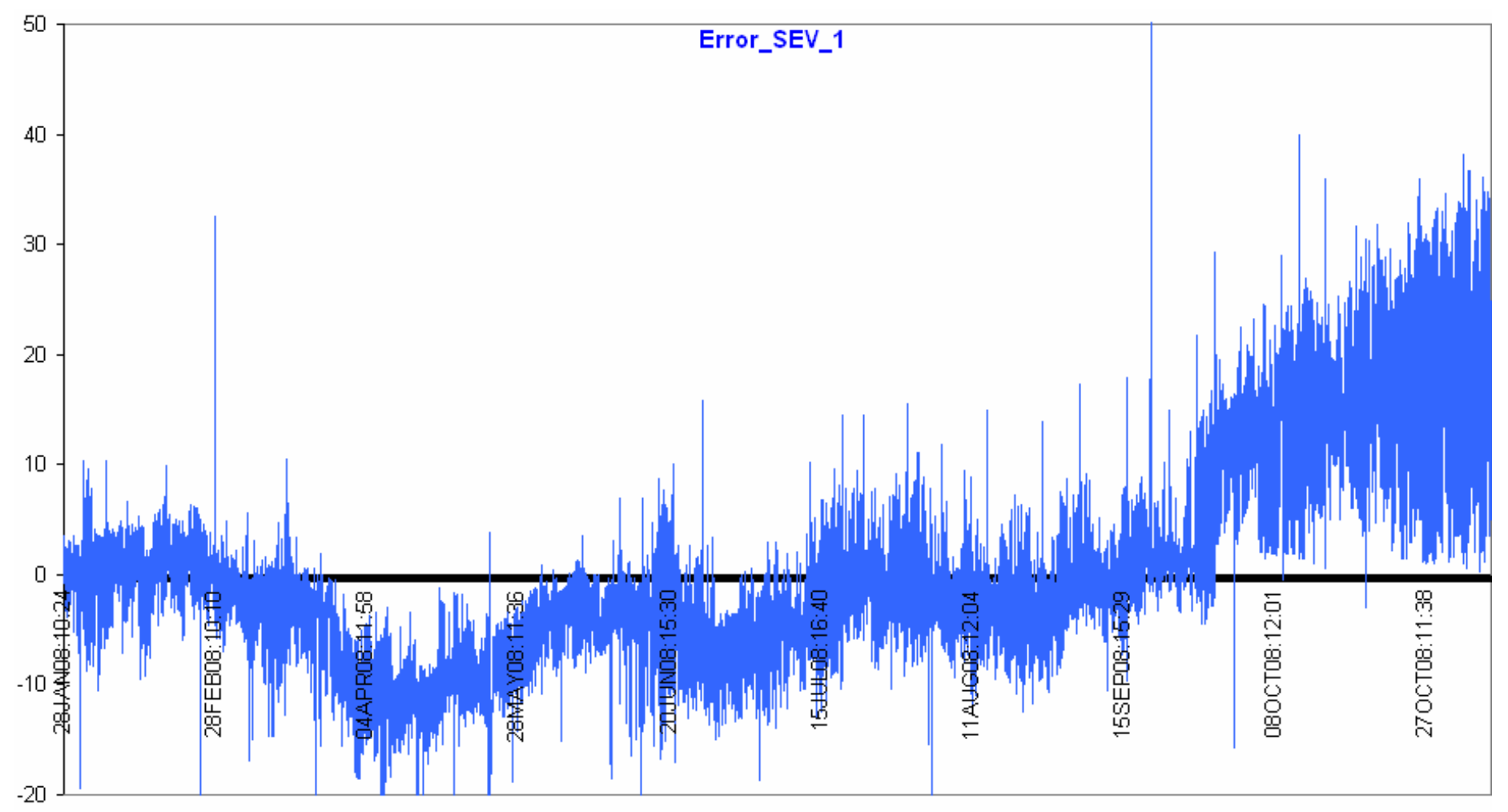


Figure 5.2: Error of SEV 2 index

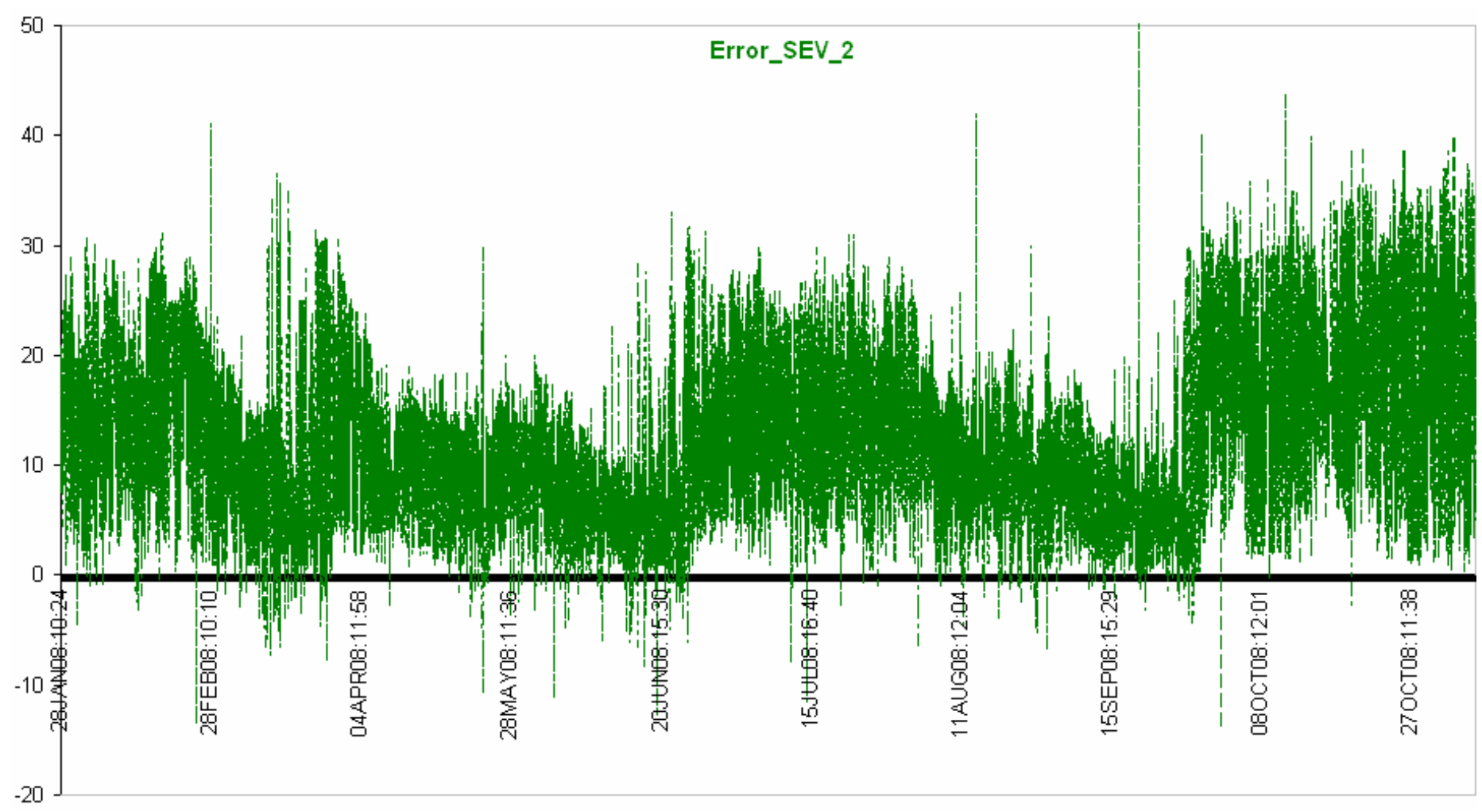


Figure 5.3: Error of SEV_3 index

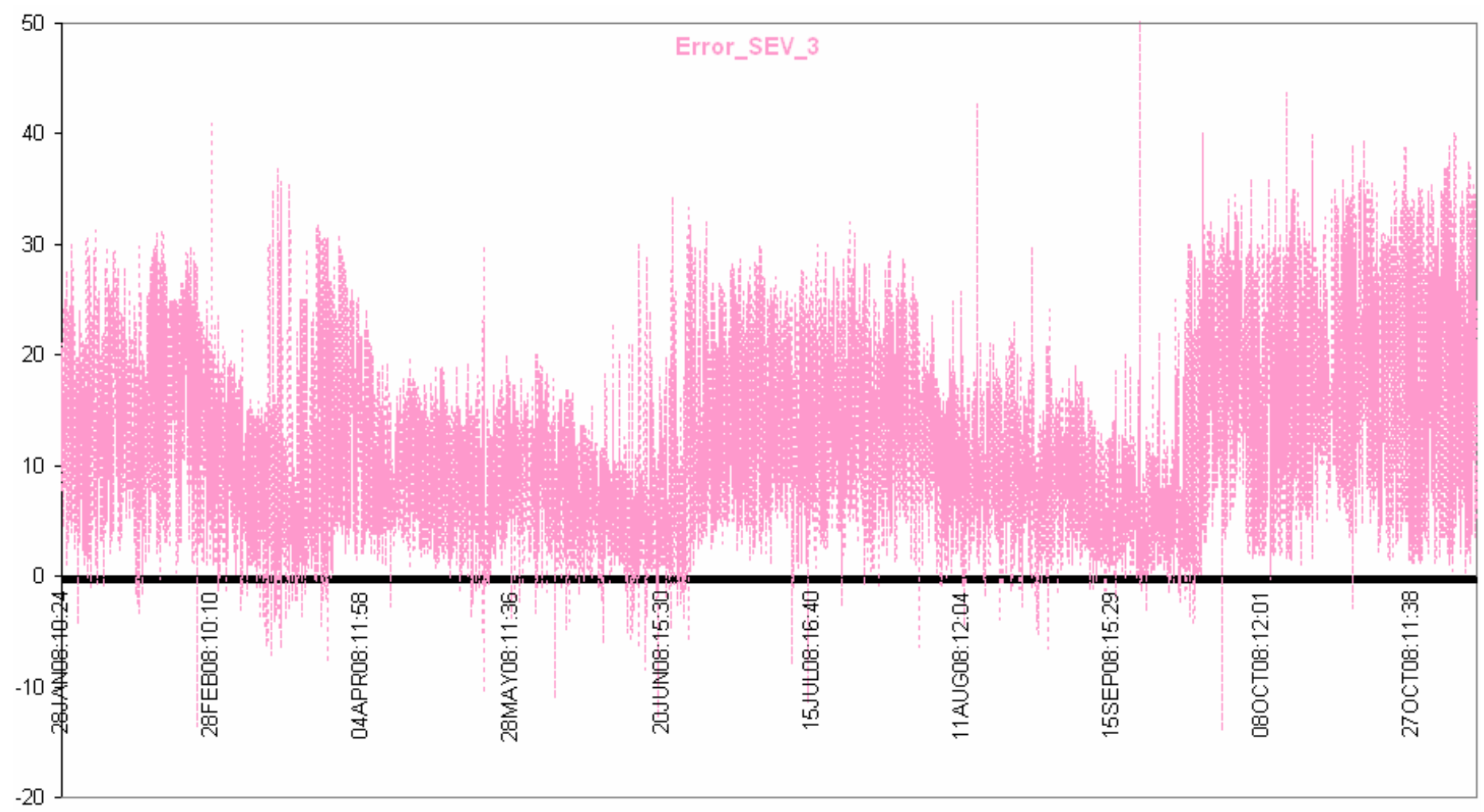


Figure 5.4: Error of TVIX index

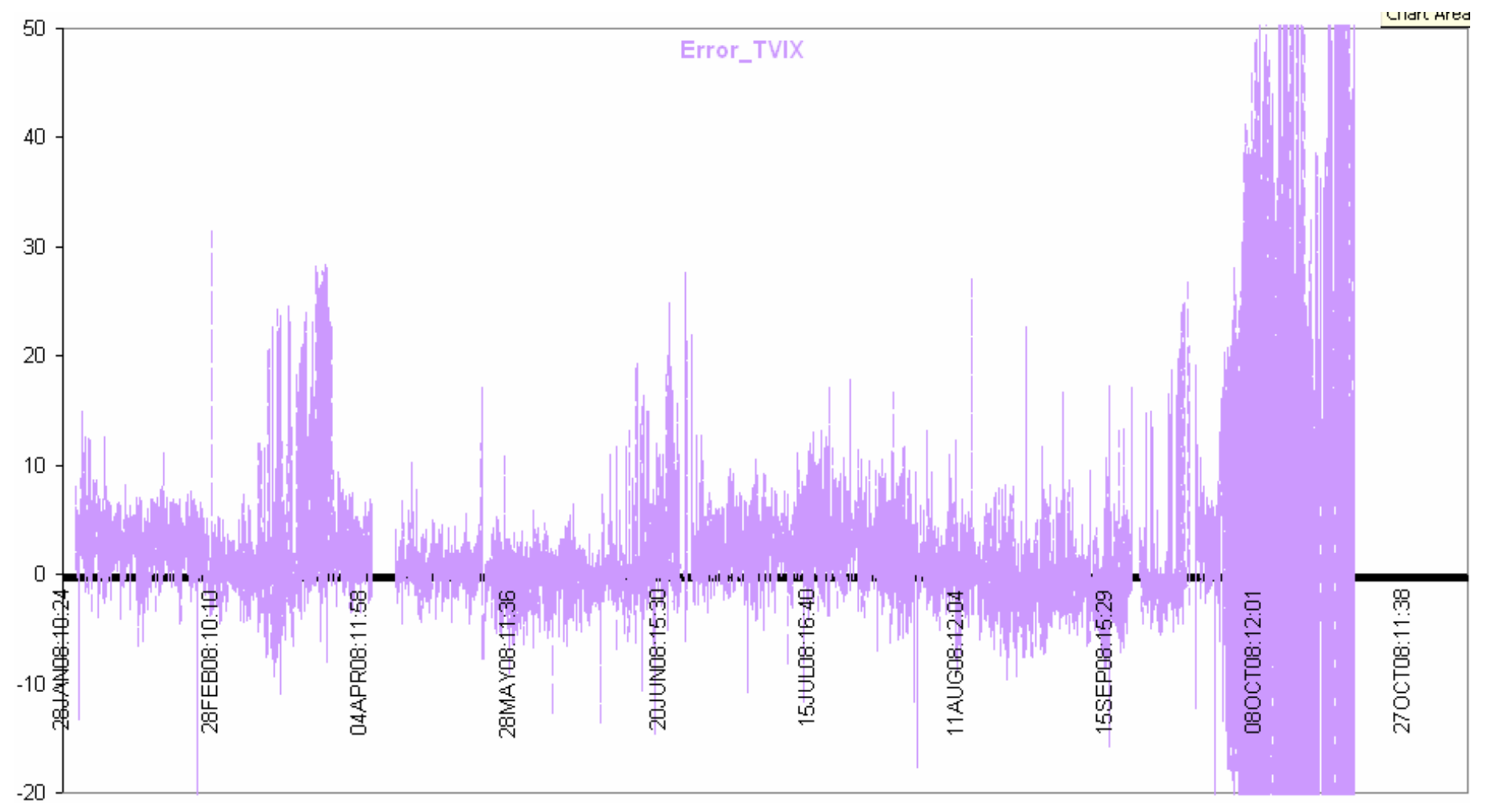


Figure 6: Error of Indexes

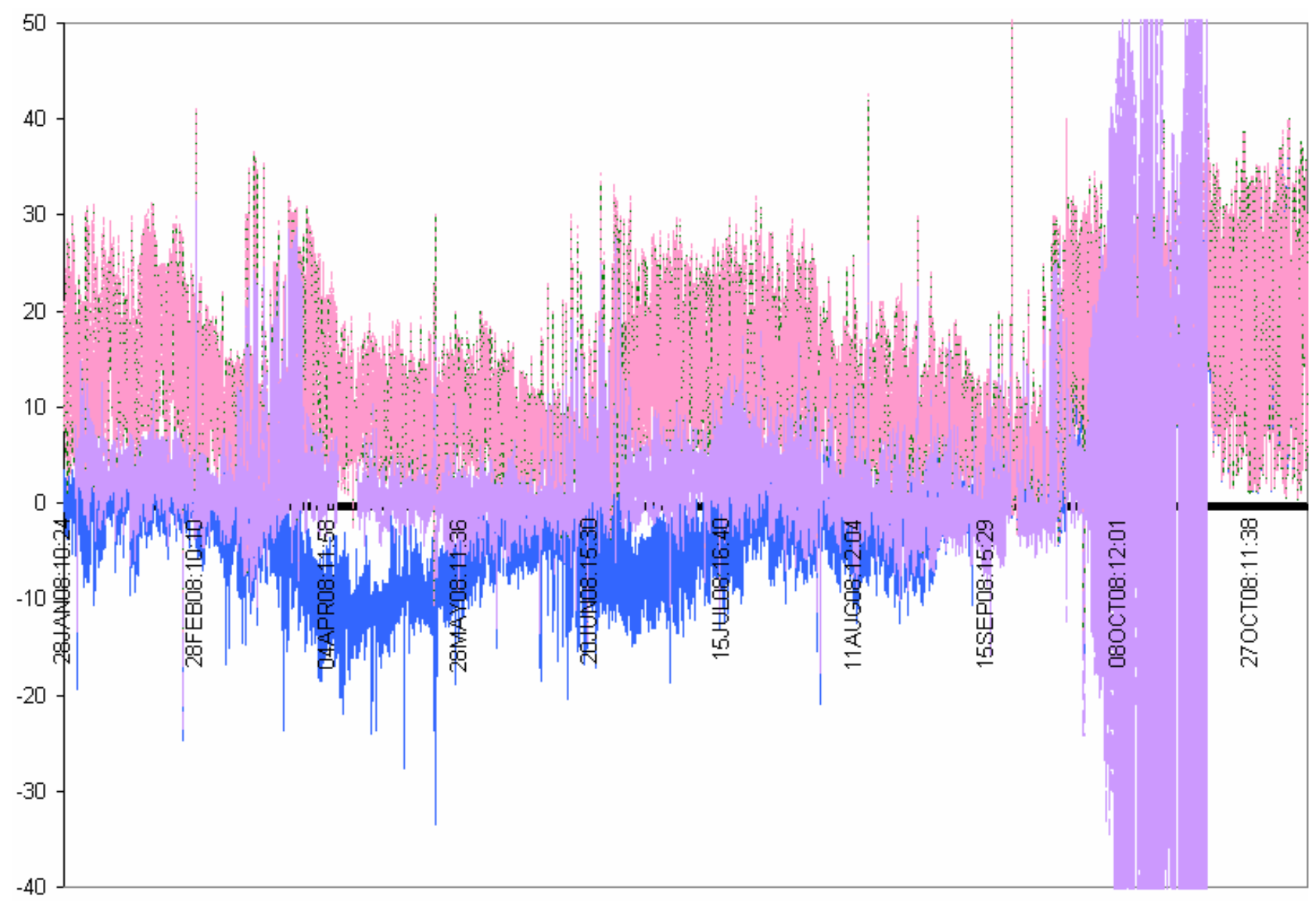


Table 1: Descriptive Statistics of Volatility Indexes

\begin{tabular}{|l|r|r|r|r|}
\hline Variable & SEV_1 & SEV_2 & SEV_3 & TVIX \\
\hline Mean & 0.37 & 0.02 & 0.000048 & 38.98 \\
\hline Std Dev & 0.01 & 0.01 & 0.000028 & 25.76 \\
\hline Kurtosis & 1.18 & 1.43 & 1.81 & 2.42 \\
\hline Kurtosis & 0.46 & 1.19 & 2.57 & 5.24 \\
\hline Minimum & 0.36 & 0.02 & 0.000024 & 16.60 \\
\hline Maximum & 0.41 & 0.04 & 0.000147 & 156.75 \\
\hline
\end{tabular}

Table 2: Goodness of Fit of Volatility Indexes

\begin{tabular}{|l|r|r|r|r|}
\hline \multicolumn{1}{|c|}{ Measures of Goodness of Fit } & \multicolumn{1}{c|}{ SEV_1 } & \multicolumn{1}{c|}{ SEV_2 } & \multicolumn{1}{c|}{ SEV_3 } & \multicolumn{1}{c|}{ TVIX } \\
\hline Mean Square Error MSE & $2.30 \mathrm{E}-08$ & $3.84 \mathrm{E}-09$ & $1.33 \mathrm{E}-07$ & 0.38068 \\
\hline Root Mean Square Error RMSE & 0.0001516 & 0.0000620 & 0.0003648 & 0.6169900 \\
\hline Mean Absolute Percent Error MAPE & $\mathbf{0 . 0 1 5 0 3}$ & 0.09208 & 0.18429 & 0.50004 \\
\hline Mean Absolute Error MAE & 0.0000566 & 0.0000207 & 0.0001003 & 0.1754700 \\
\hline Adjusted R-Square R ${ }^{2}$ (Close to 1.000) & $\mathbf{0 . 9 9 9 8 9}$ & 0.99987 & 0.99982 & 0.99943 \\
\hline AIC & $-262,874$ & $-290,423$ & $\mathbf{- 4 4 6 , 0 9 1}$ & $-12,718$ \\
\hline SBIC & $-262,851$ & $-290,400$ & $\mathbf{- 4 4 6 , 0 6 8}$ & $-12,704$ \\
\hline
\end{tabular}


Table 3: Summary Statistics Over the Year

\begin{tabular}{|l|r|r|r|r|r|r|r|r|}
\hline \multirow{2}{*}{$\begin{array}{c}\text { March } \\
\text { 2008 }\end{array}$} & \multicolumn{1}{|c|}{ SEV_1 } & \multicolumn{1}{c|}{ SEV_2 } & \multicolumn{2}{c|}{ SEV_3 } & \multicolumn{2}{c|}{ TVIX } \\
\cline { 2 - 9 } MSE & $2.31 \mathrm{E}-08$ & \multicolumn{1}{c|}{ Put } & \multicolumn{1}{c|}{ Call } & \multicolumn{1}{c|}{ Put } & \multicolumn{1}{c|}{ Call } & \multicolumn{1}{c|}{ Put } & \multicolumn{1}{c|}{ Call } & \multicolumn{1}{c|}{ Put } \\
\hline RMSE & 0.0001519 & 0.00015 & 0.0000457 & 0.0000452 & $1.56 \mathrm{E}-07$ & $1.55 \mathrm{E}-07$ & 0.78338 & 0.81245 \\
\hline MAE & 0.0000786 & 0.0000771 & 0.0000236 & 0.0000231 & $8.05 \mathrm{E}-08$ & $7.87 \mathrm{E}-08$ & 0.26397 & 0.27636 \\
\hline MAPE & 0.02176 & 0.02136 & 0.13874 & 0.13632 & 0.27782 & 0.27277 & $7.54 \mathrm{E}-01$ & 0.77285 \\
\hline ADJ R ${ }^{2}$ & 0.98919 & 0.98712 & 0.98933 & 0.98722 & 0.98952 & 0.98734 & $\mathbf{0 . 9 9 8 8 6}$ & $\mathbf{0 . 9 9 9 1 4}$ \\
\hline AIC & -26762.31 & -25954.18 & -30416.3 & -29491.16 & $\mathbf{- 4 7 7 0 0 . 9 8}$ & $\mathbf{- 4 6 2 2 8 . 3 5}$ & -2823.69 & -2837.35 \\
\hline SBIC & -26756.98 & -25948.88 & -30410.97 & -29485.86 & $\mathbf{- 4 7 6 9 5 . 6 5}$ & $\mathbf{- 4 6 2 2 3 . 0 5}$ & -3074.72 & -2823.69 \\
\hline
\end{tabular}

\begin{tabular}{|l|r|r|r|r|r|r|r|r|}
\hline \multirow{2}{*}{\begin{tabular}{c}
\multirow{2}{*}{ June } \\
2008
\end{tabular}} & \multicolumn{2}{c|}{ SEV_1 } & \multicolumn{1}{c|}{ SEV_2 } & \multicolumn{2}{c|}{ SEV_3 } & \multicolumn{2}{c|}{ TVIX } \\
\cline { 2 - 9 } MSE & $2.26 \mathrm{E}-08$ & \multicolumn{1}{c|}{ Put } & \multicolumn{1}{c|}{ Call } & \multicolumn{1}{c|}{ Put } & \multicolumn{1}{c|}{ Call } & \multicolumn{1}{c|}{ Put } & \multicolumn{1}{c|}{ Call } & \multicolumn{1}{c|}{ Put } \\
\hline RMSE & 0.0001504 & 0.0001459 & $0.10 \mathrm{E}-09$ & \multicolumn{1}{c|}{$1.98 \mathrm{E}-09$} & $2.55 \mathrm{E}-14$ & $2.41 \mathrm{E}-14$ & 0.61369 & 0.66007 \\
\hline MAE & 0.0000748 & 0.0000718 & 0.0000226 & 0.0000217 & $7.74 \mathrm{E}-08$ & $7.53 \mathrm{E}-08$ & 0.26397 & 0.27636 \\
\hline MAPE & 0.02069 & 0.01987 & 0.13185 & 0.12659 & 0.26376 & 0.2557 & 0.7537 & 0.77285 \\
\hline ADJ R & 0.99554 & 0.99615 & 0.99546 & 0.99611 & 0.99531 & 0.99602 & $\mathbf{0 . 9 9 8 8 6}$ & $\mathbf{0 . 9 9 9 1 4}$ \\
\hline AIC & -59374.92 & -61949.31 & -67393.37 & -70282.14 & $\mathbf{- 1 0 5 5 6 8}$ & $\mathbf{- 1 0 9 9 6 8}$ & -3088.22 & -2837.35 \\
\hline SBIC & -59362.67 & -61936.99 & -67381.13 & -70269.82 & $\mathbf{- 1 0 5 5 5 6}$ & $\mathbf{- 1 0 9 9 5 5}$ & -3074.72 & -2823.69 \\
\hline
\end{tabular}

\begin{tabular}{|l|r|r|r|r|r|r|r|r|}
\hline \multirow{2}{*}{$\begin{array}{l}\text { September } \\
\text { 2008 }\end{array}$} & \multicolumn{2}{|c|}{ SEV_1 } & \multicolumn{2}{c|}{ SEV_2 } & \multicolumn{2}{c|}{ SEV_3 } & \multicolumn{2}{c|}{ TVIX } \\
\cline { 2 - 9 } MSE & $3.62 \mathrm{E}-08$ & \multicolumn{1}{c|}{ Put } & \multicolumn{1}{c|}{ Call } & \multicolumn{1}{c|}{ Put } & \multicolumn{1}{c|}{ Call } & \multicolumn{1}{c|}{ Put } & \multicolumn{1}{c|}{ Call } & \multicolumn{1}{c|}{ Put } \\
\hline RMSE & 0.0001901 & 0.0001719 & $0.35 \mathrm{E}-09$ & $3.44 \mathrm{E}-09$ & $8.20 \mathrm{E}-14$ & $6.17 \mathrm{E}-14$ & 0.61369 & 0.66007 \\
\hline MAE & 0.0000811 & 0.0000781 & 0.0000265 & 0.0000256 & $1.04 \mathrm{E}-07$ & $9.98 \mathrm{E}-08$ & 0.26397 & 0.27636 \\
\hline MAPE & 0.02206 & 0.02124 & 0.13808 & 0.13343 & 0.2762 & 0.26596 & 0.61369 & 0.77285 \\
\hline ADJ R & $\mathbf{0 . 9 9 9 2 3}$ & $\mathbf{0 . 9 9 9 4 5}$ & 0.99914 & 0.99942 & 0.99892 & 0.99932 & 0.99886 & 0.99914 \\
\hline AIC & -104093 & -107888 & -116962 & -121276 & $\mathbf{- 1 8 3 0 5 0}$ & $\mathbf{- 1 8 9 2 7 2}$ & -3088.22 & -2837.35 \\
\hline SBIC & -104080 & -107874 & -116949 & -121262 & $\mathbf{- 1 8 3 0 3 0}$ & $\mathbf{- 1 8 9 2 5 2}$ & -3074.72 & -2823.69 \\
\hline
\end{tabular}

\begin{tabular}{|l|r|r|r|r|r|r|r|r|}
\hline \multirow{2}{*}{$\begin{array}{l}\text { December } \\
\text { 2008 }\end{array}$} & \multicolumn{2}{|c|}{ SEV_1 } & \multicolumn{2}{c|}{ SEV_2 } & \multicolumn{2}{c|}{ SEV_3 } & \multicolumn{2}{c|}{ TVIX } \\
\cline { 2 - 9 } MSE & \multicolumn{1}{c|}{ Call } & \multicolumn{1}{c|}{ Put } & \multicolumn{1}{c|}{ Call } & \multicolumn{1}{c|}{ Put } & \multicolumn{1}{c|}{ Call } & \multicolumn{1}{c|}{ Put } & \multicolumn{1}{c|}{ Call } & \multicolumn{1}{c|}{ Put } \\
\hline RMSE & 0.0002453 & $0.099 \mathrm{E}-08$ & $9.85 \mathrm{E}-09$ & $8.07 \mathrm{E}-09$ & $3.30 \mathrm{E}-13$ & $2.76 \mathrm{E}-13$ & 0.61369 & 0.66007 \\
\hline MAE & 0.0000978 & 0.0000925 & 0.0000992 & 0.00000898 & $5.74 \mathrm{E}-07$ & $5.25 \mathrm{E}-07$ & 0.78338 & 0.81245 \\
\hline MAPE & 0.02597 & 0.02448 & 0.15884 & 0.0000342 & $1.71 \mathrm{E}-07$ & $1.68 \mathrm{E}-07$ & 0.26397 & 0.27636 \\
\hline ADJ R & $\mathbf{0 . 9 9 9 6 8}$ & $\mathbf{0 . 9 9 9 7 8}$ & 0.99963 & 0.99975 & 0.99951 & 0.99967 & 0.99886 & 0.99914 \\
\hline AIC & -119189 & -119175 & -132163 & -132149 & $\mathbf{- 2 0 6 0 2 3}$ & $\mathbf{- 2 0 6 0 0 2}$ & -3088.22 & -2837.35 \\
\hline SBIC & -133260 & -133246 & -147531 & -147517 & $\mathbf{- 2 2 8 9 5 3}$ & $\mathbf{- 2 2 8 9 3 2}$ & -3074.72 & -2823.69 \\
\hline
\end{tabular}


Table 4: Summary of Actual and Predicted Prices

\begin{tabular}{|c|c|c|c|c|c|c|c|c|c|c|}
\hline & \multicolumn{2}{|c|}{ Actual Price } & \multicolumn{8}{|c|}{ Predicted Prices } \\
\hline Variable & C_Price & P_Price & C_SEV_1 & P_SEV_1 & C_SEV_2 & P_SEV_2 & C_SEV_3 & P_SEV_3 & TVIX & P_TVIX \\
\hline Mean & 15.09 & 24.39 & 21.79 & 28.52 & 10.04 & 16.77 & 10.18 & 16.91 & 17.94 & 17.60 \\
\hline Std Dev & 10.75 & 21.15 & 17.33 & 23.24 & 16.51 & 25.35 & 16.45 & 25.27 & 16.73 & 17.06 \\
\hline Minimum & 0.1 & 0 & $2.87 \mathrm{E}-100$ & $-1.89 \mathrm{E}-14$ & 0 & $-8.3 \mathrm{E}-14$ & 0 & $-7.9 \mathrm{E}-14$ & $.02 \mathrm{E}-26$ & $2.02 \mathrm{E}-07$ \\
\hline$\overline{\text { Maxi }}$ & 80.00 & 210.00 & 130.15 & 208.69 & 130.05 & 208.69 & 130.05 & 208.69 & 130.23 & 208.7 \\
\hline
\end{tabular}

Note: $\mathrm{C}$ and $\mathrm{P}$ denote call and put, respectively.

Table 5: Summary Statistics of Forecast Errors

\begin{tabular}{|l|r|r|r|r|}
\hline & \multicolumn{4}{|c|}{ Error = actual price - predicted price } \\
\hline Variable & error_SEV_1 & error_SEV_2 & error_SEV_3 & error_TVIX \\
\hline Mean & $\mathbf{0 . 4 5}$ & 12.20 & 12.26 & 1.40 \\
\hline Std Dev & 9.46 & 7.85 & 7.90 & 11.84 \\
\hline Minimum & -33.45 & -13.97 & -13.97 & -96.23 \\
\hline Maximum & 58.31 & 58.31 & 58.31 & 71.63 \\
\hline Sum & $\mathbf{6 8 0 0 . 7 4}$ & 184041.61 & 184891.54 & 18475.16 \\
\hline
\end{tabular}

Table 6: Summary Statistics of Percentage Errors

\begin{tabular}{|l|r|r|r|r|}
\hline Variable & \%_error_SEV_1 & \%_error_SEV_2 & \%_error_SEV_3 & \%_error_TVIX \\
\hline Mean & -18.35 & 80.40 & 80.71 & $\mathbf{- 3 . 4 7}$ \\
\hline Std Dev & 101.50 & 32.34 & 32.47 & 91.76 \\
\hline Minimum & -2367.00 & -131.22 & -131.22 & -1762.51 \\
\hline Maximum & 100 & 100 & 100 & 100 \\
\hline
\end{tabular}


Table 7: Correlations between the Volatility Indexes and Index

\begin{tabular}{|l|l|l|l|c|}
\hline Correlations & SEV_1 & SEV_2 & SEV_3 & TVIX \\
\hline Index & $\mathbf{- 0 . 9 6 4 6 2}$ & -0.95044 & -0.92128 & -0.66855 \\
\hline
\end{tabular}

\begin{tabular}{|c|c|c|c|c|}
\hline Correlations & SEV_1 & SEV_2 & SEV_3 & TVIX \\
\hline Index & & & & \\
\hline March 2008 & -0.99958 & -0.99909 & -0.99798 & 0.31342 \\
\hline
\end{tabular}

\begin{tabular}{|l|l|l|l|l|}
\hline June 2008 & $\mathbf{- 0 . 9 9 9 3 6}$ & -0.99855 & -0.99681 & -0.48684 \\
\hline
\end{tabular}

\begin{tabular}{|l|l|l|l|l|}
\hline September 2008 & $\mathbf{- 0 . 9 9 7 6 5}$ & -0.99450 & -0.98722 & -0.68363 \\
\hline
\end{tabular}

\begin{tabular}{|l|l|l|l|l|}
\hline December 2008 & $\mathbf{- 0 . 9 6 4 6 2}$ & -0.95044 & -0.92128 & -0.66855 \\
\hline
\end{tabular}

Table 8: Summary of Criteria for Best Fitting Models

\begin{tabular}{|l|l|l|l|l|}
\hline \multicolumn{1}{|c|}{ Criteria } & SEV_1 & SEV_2 & SEV_3 & TVIX \\
\hline MSE & & & & \\
\hline RMSE & & & & \\
\hline MAE & & & & \\
\hline MAPE & & & & \\
\hline Adjusted R ${ }^{2}$ & & & & \\
\hline AIC & & & & \\
\hline SBIC & & & & \\
\hline Error & & & & \\
\hline Percent error & & & & \\
\hline APM & & & \\
\hline Correlations & & & \\
\hline
\end{tabular}

